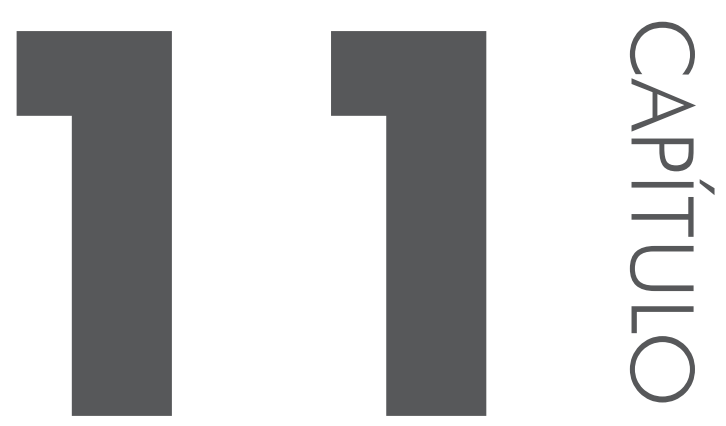

\title{
Inglês como língua franca: representações e práticas de alunos e professores de língua inglesa no Brasil
}

Jeová Araújo Rosa Filho

Mayara Volpato

Gloria Gil

\subsection{INTRODUC̣ÃO}

Ao se levantar uma discussão sobre as repercussões do Inglês como Língua Franca (ILF) em contextos de ensino e aprendizagem, o entendimento do fenômeno de globalização torna-se um ponto de partida para situarmos o nosso problema de pesquisa. O conceito de globalização, no entanto, é multidimensional e se desdobra em diversas disciplinas acadêmicas: trata-se de um tópico tão vasto que um único arcabouço teórico não o explicaria completamente (KUMARAVADIVELU, 2008).

A globalização está relacionada a uma série de forças que atuam expandindo, acelerando e intensificando interconexões ao redor do mundo. Nesse contexto, o inglês é representado como uma língua de comunicação global que impulsiona e é impulsionada pelo fenômeno de globalização. A respeito disso, Jenkins, Cogo e Dewey (2011) apontam que a língua inglesa se tornou uma língua franca (ILF doravante) cujo uso em escala mundial pode ser justificado pela globalização, assim como o avanço da globalização pode ser justificado pela emergência de uma língua franca. Portanto, entendemos a relação entre ILF e globalização como duas forças convergentes e, sobretudo, constituintes entre si. 
No contexto de uso de uma língua para comunicação global, a noção de propriedade sobre a língua e a figura do falante nativo são amplamente discutidas e problematizadas. Grande é o número de teóricos (HULMBAUER et al., 2008; JENKINS, 2007; CRYSTAL, 2003) que apontam para uma democratização e universalização do inglês que vem sendo apropriado para o uso internacional, contrapondo uma categorização binária estabelecida pela dicotomia de variedades nativas/não nativas. Apesar disso, o falante não nativo ainda é comumente visto como um usuário deficiente de uma língua que pertence ao outro: o nativo. Portanto, a fim de se desafiar tal relação de assimetria entre nativos e não nativos, teóricos enfatizam a urgência em se reconstruir a identidade do falante não nativo como um legítimo usuário de uma língua franca e não mais como um falante deficiente de uma variante nativa prestigiosa do inglês (COOK, 1999; SEIDLHOFER, 2001).

O presente capítulo visa discutir as repercussões do ILF em um contexto formal de ensino e aprendizagem de línguas, atentando para as situações de uso do inglês dentro e fora da sala de aula e buscando entender até que ponto as crenças de professores e alunos se aproximam (ou não) do ILF.

Primeiramente, buscamos levantar uma breve discussão teórica acerca do conceito de ILF, bem como suas possíveis implicações pedagógicas. Em seguida, apresentamos o contexto de investigação, os participantes do estudo e a metodologia de coleta de dados. Por fim, discutimos os resultados alcançados visando contribuir com o ensino de inglês no Brasil dentro de uma perspectiva que represente seu status de língua franca a partir de uma abordagem que garanta a diversidade linguística e cultural, o reconhecimento das culturas locais, o questionamento de estereótipos e preconceitos e, sobretudo, o desenvolvimento de uma perspectiva intercultural. ${ }^{1}$

\subsection{ILF: UMA VARIEDADE OU UMA FUNÇÃO DA LÍNGUA?}

Muitos são os termos usados nomear o amplo uso do inglês em escala mundial. Inglês como lingua internacional, ingleses globais ou inglês global são alguns dos exemplos. Aqui fazemos uso da noção de ILF, uma vez que este parece ser um termo mais amplo, abarcando contextos multilíngues em que o idioma é usado inter e intranacionalmente ${ }^{2}$.

\footnotetext{
1 De acordo com Kramsch (1998), a perspectiva intercultural envolve reflexão entre culturas diferentes. Um falante intercultural seria aquele consciente sobre a relação entre uma certa língua e seu contexto específico, capaz de interagir em fronteiras culturais, prever possíveis mal-entendidos e lidar com as demandas sociais e cognitivas intrísecas na relação com o outro.

2 Os contextos de uso do ILF envolvem tanto falantes de L1 diferentes, quanto falantes de uma mesma língua materna.
} 
Mas afinal, do que se trata uma língua franca? De origem latina, o termo lingua franca se refere primordialmente a uma língua de contato usada entre povos que não compartilham uma primeira língua e é comumente entendida como uma segunda (ou subsequente) língua de seus falantes (JENKINS, 2007, p. 1). Originalmente, o termo se refere a uma língua de natureza híbrida, sem falantes nativos, mas devido à situação sem precedência do inglês, seu uso extendeu-se a interações que incluem falantes dos círculos internos e externos ${ }^{3}$.

Um outro questionamento: seria o ILF uma variedade do inglês usada para comunicação global que assumiu características específicas e podem ser compreendidas sob a ótica da variedade linguística? As respostas a essa pergunta parecem dividir opiniões. Para Friedrich e Matsuda (2010), por exemplo, ILF deve ser definido como uma função da língua inglesa em um contexto mundial e não como uma variedade linguística. Tal pressuposto está calcado no argumento de que a noção do ILF como uma variedade implicaria, segundo os autores, a possibilidade de haver uma variedade do inglês, ou um conjunto restrito delas, a ser usada em situações de comunicação internacional. Assim, a caracterização do termo ILF é elaborada estritamente no que diz respeito ao seu uso em diferentes contextos.

Diferentemente dos autores anteriormente citados, Jenkins, Cogo e Dewey (2011) entendem o conceito de ILF como algo situado no que chamam de paradigma do Inglês Global. Nessa perspectiva, todos os usuários do inglês como ILF (mesmo falantes do inglês como primeira língua) o aprenderam como uma língua adicional, ou seja, acrescida à sua primeira língua (L1). Portanto, a noção de ILF aqui diz respeito a uma língua que se desenvolve além das normas de uma 'origem' ou de centro normativo baseado na ideia de uma língua padrão. Nesse paradigma, o inglês faz parte de um modelo de interação no qual falantes não nativos representam a maior parte das situações comunicativas no mundo. Assim, a noção de propriedade da língua por falantes nativos, em tese, se desconstrói e o sotaque estrangeiro passa a ser visto como constituinte identitário e não mais como um problema a ser resolvido (ver também SEIDLHOFER, 2011; HULMBAUER et al., 2008).

\footnotetext{
3 A noção de círculos concêntricos para mapeamento do uso do inglês no mundo foi desenvolvida pelo linguista indiano Braj B. Kachru como tentativa de sistematizar um fenômeno linguístico de dimensões sem precedentes em termos de dispersão linguística. De acordo com o autor, os "world Englishes" podem ser organizados em três círculos concêntricos: o interno (onde o inglês é usado como primeira língua); o externo (onde o inglês desempenha o papel de uma segunda língua, em um contexto multilíngue); e o círculo em expansão (onde o inglês tem papel de língua internacional).
} 
$\mathrm{Na}$ tentativa de operacionalizar a noção do ILF como uma variedade linguística, os estudos realizados por Jenkins nos últimos quinze anos têm ganhado grande reconhecimento. O projeto conhecido como Lingua Franca Core (LFC) tem como objetivo fazer um levantamento sobre quais aspectos da pronúncia são fundamentais para a inteligibilidade em um contexto de comunicação internacional. Inteligibilidade é, portanto, a palavra-chave no ensino de pronúncia e representações homogêneas de variedades nativas de prestígio passam a ser questionadas nesse novo cenário de uso do inglês.

A constituição do banco de dados do LFC é proveniente de informantes de uma vasta gama de L1, sendo que os dados foram coletados ao longo de vários anos sob diferentes métodos, como observação de campo, gravação de pares de informantes com L1 diferentes, tarefas em grupo, além de análise de produção e recepção de acentos em posições nucleares. A análise das amostras teve como objetivo principal observar quais “erros" de pronúncia repercutiram em problemas de inteligibilidade em uma situação de comunicação com falantes de L1 distintas. Outros elementos de análise linguística, como a sintaxe, as cópulas, os auxiliares, poderiam igualmente reforçar a ideia do ILF como uma variedade, já que pesquisas sociolinguísticas demonstram que línguas francas pressupõem uma certa simplificação gramatical e isso se confirma no caso do ILF. No entanto, o foco do LFC se restringiu a aspectos da pronúncia, uma vez que o objetivo maior do projeto era criar um núcleo fonológico do ILF.

No mesmo direcionamento, outros estudos empíricos em ILF já buscam explorar outros níveis da linguagem, a exemplo da investigação pragmática que recebeu muita atenção de teóricos como Firth (1996), Meierkord (1996; 2002), House $(1999 ; 2002)$ e Penz (2003) e, mais recentemente, níveis léxico-gramaticais vêm sendo igualmente explorados pela iniciativa de Seidlhofer (2011) que, a partir de diferentes bancos de dados, pôde apontar algumas tendências particulares do ILF, como o apagamento da flexão da terceira pessoa do singular, o uso indiferente de pronomes relativos who e which, a omissão de artigos definidos e indefinidos quando obrigatórios, a redundância pelo acréscimo de preposições, além da pluralização de substantivos que não possuem forma de plural no inglês.

No Brasil, muitos estudos em inteligibilidade têm dialogado com o LFC e colaborado com a ampliação do projeto de criação de um núcleo fonológico do ILF, a exemplo de Cruz (2006; 2012) e Reis e Cruz (2010), que buscaram investigar inteligibilidade em diferentes contextos de interação entre falantes de nacionalidades distintas e mapear categorias de pronúncia que implicaram em falhas comunicativas, correlacionando os resultados encontrados com as categorias propostas pelo LFC. 


\subsection{IMPLICAC̣ÕES PEDAGÓGICAS}

A noção de ILF implica a constituição de um novo paradigma de uso do inglês que extrapola as normas de um centro normativo e desafia a ideia de propriedade da língua pela desconstrução do mito do falante nativo como um modelo-alvo a ser seguido. Essas novas concepções são as bases para uma reorganização de um novo modelo de ensino de línguas, que até então está calcado no paradigma de Inglês como Língua Estrangeira (ILE).

Embora semelhantes no acrônimo, muitas são as diferenças conceituais entre ILF e ILE, como pode ser observado no Quadro 11.1.

\begin{tabular}{|l|l|l|}
\hline & EFLLingua Estrangeira & ELF Lingua Franca \\
\hline $\begin{array}{l}\text { Normas } \\
\text { Linguístico- } \\
\text { culturais }\end{array}$ & Pré-existentes, reafirmadas & Ad hoc ${ }^{4}$, negociadas \\
\hline Objetivos & $\begin{array}{l}\text { Integração, parceria em uma } \\
\text { comunidade de falantes nativos }\end{array}$ & $\begin{array}{l}\text { Inteligibilidade, comunicação tanto entre } \\
\text { não nativos como entre esses e nativos }\end{array}$ \\
\hline Processos & Immitação, adoção & Acomodação, adaptação \\
\hline
\end{tabular}

Quadro 11.1 - Comparação entre EFL e ELF (SEIDLHOFER, 2011, p. 18).

Considerando o status multicultural do ILF, os objetivos pedagógicos não estão mais calcados no alcance de uma proficiência que espelhe o falante nativo, o que, para muitos aprendizes, é uma meta distante e inalcançável. Agora, muitos pesquisadores apontam para a urgência na formação de um falante intercultural ${ }^{5}$ (BYRAM, 1997; CORBET, 2003; KRAMSCH, 1998; LIDDICOAT et al.,1999) e no desenvolvimento de habilidades comunicativas que permitam ao aprendiz alcançar objetivos viáveis de mediação e exploração cultural.

\footnotetext{
4 Do latim "para esta finalidade". No contexto de ILF, sugere que as normas sejam trabalhadas de acordo com a necessidade.

5 Byram (1997) propõe uma ampliação do conceito de Competência Comunicativa ao ligá-lo à educação intercultural. Para o autor, a Competência Comunicativa Intercultural é uma capacidade de uso da linguagem em contextos nos quais estão em jogo identidades culturais diferentes. Assim, um sujeito competente comunicativa e interculturalmente tem a capacidade de inserir-se em contextos diferentes, familiarizar-se com eles e de respeitar as diferentes possibilidades de construir identidade que as outras pessoas adotaram.
} 
Mckay (2002) sustenta esse paradigma e desafia a perspectiva tradicional do ensino de inglês como língua estrangeira a partir da promoção de uma competência intercultural; da conscientização sobre outras variedades do inglês; do multilingualismo em aula; do uso de materiais que incluem culturas locais e internacionais e, por fim, a partir do desenvolvimento de uma metodologia culturalmente e socialmente sensível.

Em tese, essa discussão não é uma novidade no contexto educacional brasileiro. No entanto, não há qualquer direcionamento metodológico explicitamente relacionado ao ILF. Documentos oficiais como os Parâmetros Curriculares Nacionais (BRASIL, 1998) e o Programa Nacional do Livro Didático (BRASIL, 2015) enfatizam a relevância em habilitar os aprendizes a interagir em diferentes contextos culturais e, sobretudo, conscientizá-los sobre seus papéis como cidadãos de suas comunidades locais e do mundo, mas não há menções diretamente relacionadas ao ILF.Além disso, muitossão os desafios relacionadosà implementação dessa perspectiva e, comumente, uma abordagem intercultural que se fundamente nas premissas do ILF é má interpretada ou negligenciada (GIMENEZ, 2001).

\subsection{METODOLOGIA}

Considerando as implicações discutidas, esta seção apresenta resultados das possíveis repercussões do ILF em um contexto formal de ensino. Assim, analisamos se os alunos e professores investigados entendem o ILF como uma variedade linguística e de que maneira tais representações ganham forma nas abordagens pedagógicas, no material didático usado, bem como nos usos do inglês em contextos fora da sala de aula.

A investigação empírica aconteceu no Curso Extracurricular da Universidade Federal de Santa Catarina (UFSC). A escolha por tal contexto se deu devido à acessibilidade que os pesquisadores têm às salas de aula. O Extracurricular oferece cursos de cinco línguas (alemão, francês, italiano, espanhol e inglês) para membros da comunidade acadêmica (alunos, professores e funcionários) ou outras pessoas que se interessem em estudar línguas adicionais. Os professores do curso de inglês são admitidos por processo seletivo e devem possuir algum tipo de vínculo com a universidade, sendo geralmente alunos de graduação ou pós-graduação do curso de Letras com habilitação em Língua Inglesa. Duas séries de livros são usadas como material didático no curso de inglês. Três volumes da quarta edição do livro Interchange, publicados pela Cambridge University Press, e dois volumes do livro New American Inside Out, publicados pela Macmillan. A primeira série de livros é usada entre os níveis básicos e pré-intermediários e a segunda série, entre os níveis intermediários e avançados. De forma geral, os livros adotados pelo curso 
seguem a linha metodológica da abordagem comunicativa, na qual a língua é vista como uma ferramenta para a comunicação e a cultura é associada à ideia de identidade nacional.

Além disso, apesar desses materiais didáticos serem livros globais, produzidos para o mundo inteiro e não para uma comunidade específica, poucos são os momentos em que variedades linguísticas diferentes da americana e britânica são apresentadas nos programas de áudio. Portanto, a exposição de outras variedades do inglês geralmente ocorre mediante atividades adaptadas de outras fontes e trazidas pelos professores.

A pesquisa aqui apresentada foi realizada com 104 alunos do nível um ao oito do curso de inglês (sendo nível um o mais básico oferecido pelo programa e oito o mais avançado). Desse total, a maior parte dos alunos participantes possui de um a cinco anos de estudo do idioma em instituições formais de ensino. A Figura 11.1 apresenta a porcentagem de alunos por nível, sendo que a média é de treze alunos inscritos por turma.

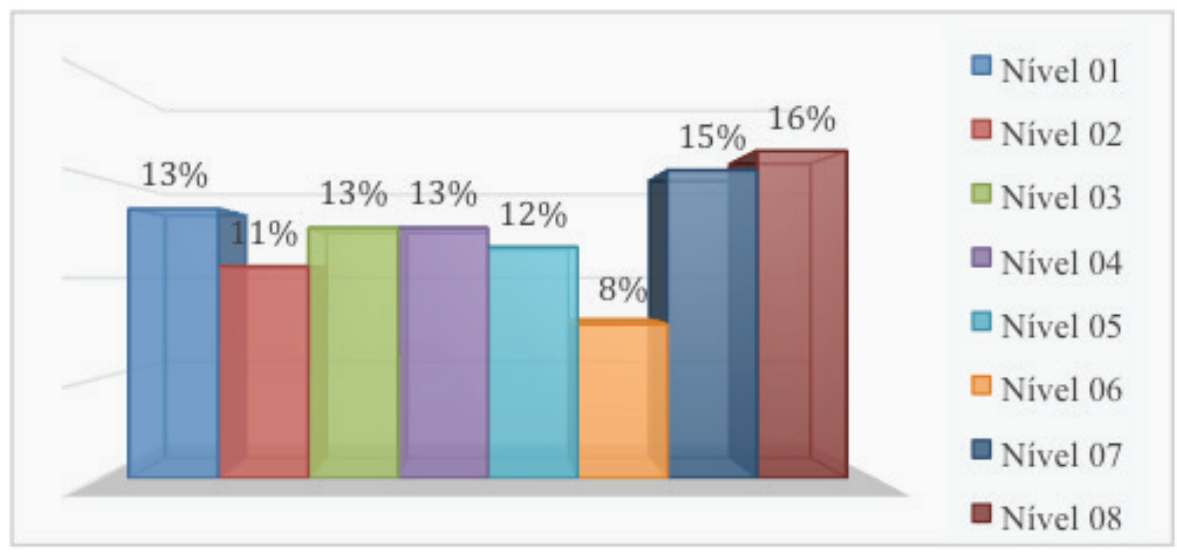

Figura 11.1 - Gráfico da porcentagem de alunos por nível.

Um total de oito professores também participou desse estudo. A maioria deles estuda em nível de pós-graduação, com doutorado ou mestrado em andamento na área específica de língua inglesa. O grupo tem experiência de ensino que varia entre cinco e trinta anos e possui idades bem distintas, entre 24 e 54 anos, como pode ser observado no Quadro 11.2.

Tendo em vista o objetivo apresentado nesse trabalho, dois instrumentos de coleta de dados foram desenvolvidos, um para os professores (ANEXO 1) e outro para os alunos (ANEXO 2). Aos alunos foram feitas perguntas que possibilitassem aos pesquisadores entender se suas representações e usos do inglês se aproximavam da noção do ILF. Para tanto, foram elaboradas questões sobre os contextos de uso da língua inglesa fora da sala de aula, a associação do inglês com 
países específico, ou ainda sobre a pronúncia "abrasileirada”, com o propósito de perceber se o falar com sotaque estrangeiro é visto como um problema ou um constituinte identitário.

\begin{tabular}{|c|c|c|c|}
\hline Nome & Idade & Fomação acadêmica & Tempo de ensino \\
\hline Professor 1 & 24 & Doutorado em andamento & 6 anos \\
\hline Professor 2 & 27 & Mestrado em andamento & 5 anos \\
\hline Professor 3 & 28 & Mestrado em andamento & 10 anos \\
\hline Professor 4 & 29 & Doutorado em andamento & 7 anos \\
\hline Professor 5 & 30 & Mestrado em andamento & 14 anos \\
\hline Professor 6 & 30 & Doutorado em andamento & 8 anos \\
\hline Professor 7 & 36 & Ensino Médio completo & 17 anos \\
\hline Professor 8 & 54 & Ensino Superior completo & 30 anos \\
\hline
\end{tabular}

Quadr• 11.2 - Relação de professores participantes.

O questionário dos professores seguiu o mesmo formato do questionário dos alunos, porém com questionamento adicional relativo à prática didática. A partir disso, buscou-se entender de que forma suas abordagens em sala enfatizam ou não o ILF. Os professores foram também questionados sobre suas visões acerca do livro didático e sobre a inclusão de materiais extras que conscientizem os alunos sobre as variedades do inglês pelo mundo.

A partir da implementação dos instrumentos de coleta de dados descritos acima, buscamos responder a seguinte pergunta: de que modo as representações e práticas de alunos e professores apontam para uma aproximação ou distanciamento da noção de ILF como uma variedade linguística?

\subsection{RESULTADOS E DISCUSSÃO}

A promoção do inglês como uma língua de comunicação global está estritamente relacionada ao fenômeno da globalização. Nesse contexto, em que interações transnacionais são cada vez mais frequentes, o inglês passa a ser visto como uma língua franca, ou seja, dissociada das normas de uma origem ou de um centro normativo (JENKINS, 2006). Tal mudança traz consigo uma série de repercussões pedagógicas que se baseiam em um paradigma de ensino calcado no desenvolvimento de uma competência intercultural, que desconstrói o modelo do falante nativo como alvo de aprendizagem de uma língua adicional. Com isso 
em mente, esse estudo se valeu de questionários aplicados a professores e alunos para que fosse possível discutir as repercussões do ILF em um contexto formal de ensino e aprendizagem de línguas no Brasil.

Uma vez que a noção de ILF está relacionada a uma variedade linguística usada inter e intranacionalmente com falantes de uma mesma língua ou de línguas diferentes, buscamos primeiramente analisar em quais contextos a língua inglesa é usada fora do ambiente da sala de aula. A partir das respostas coletadas (Gráfico 11.2), notou-se que a maior parte das situações de uso do idioma (79\%) acontece em espaços virtuais comumente mediados pela internet.

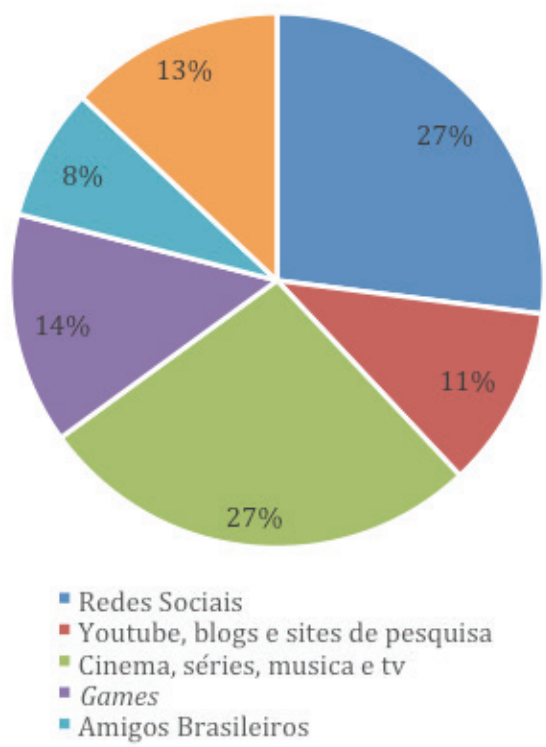

Figura 11.2 - Gráfico do uso do inglês fora da sala de aula.

A Figura 11.2 evidencia como os espaços de interação se multiplicaram com o avanço tecnológico e como o surgimento de ambientes virtuais de interação, como redes sociais, por exemplo, são, por excelência, espaços de uso do ILF que envolvem falantes de diferentes L1 em situações de comunicação.

A mesma análise foi feita em relação ao grupo de seis professores participantes e, a partir das respostas, chegou-se a uma conclusão parecida. A maior parte deles diz usar o idioma em situações fora da sala de aula ao se comunicar com amigos, colegas professores ou em situações de interação virtual mediadas pela internet. Portanto, nas situações comunicativas analisadas, o inglês tem sido usado por professores e alunos como uma língua franca em contextos de comunicação global e local com falantes de uma mesma L1 ou de L1 diferentes.

Em seguida, questionamos o que influenciou os alunos a estudarem o idioma. Os informantes deveriam escolher respostas objetivas sugeridas pelo próprio 
questionário (ANEXO 2). Do total de 104 alunos, 30 e 36 apontaram como principal motivo a comunicação com pessoas de diferentes nacionalidades (Figura 11.3). Em contrapartida, um total de 43 informantes escolheu o desenvolvimento da compreensão de uma cultura específica como menor de seus interesses.

Mais relevantes

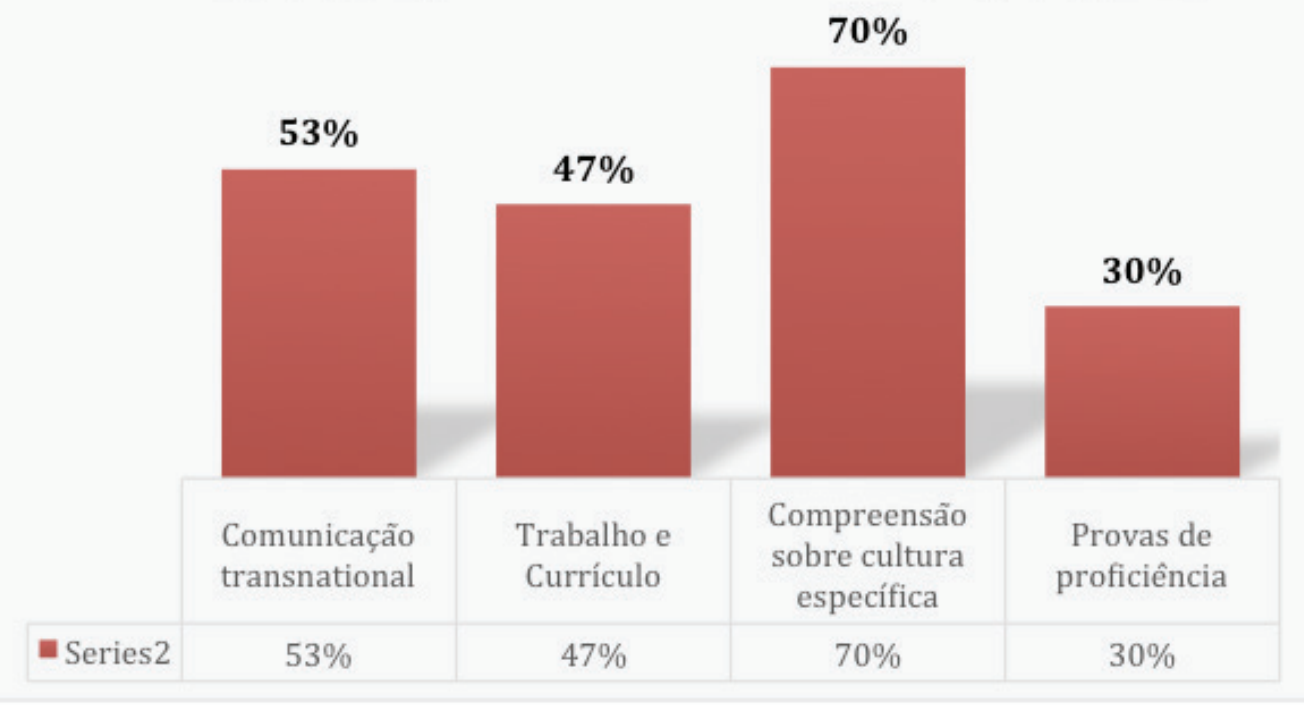

Figura 11.3 - Gráfico dos motivos mais e menos relevantes para 0 estudo de inglês.

O contraste desses dados encadeia conclusões interessantes, já que, embora a maioria dos participantes tenha apontado a compreensão de uma cultura específica como alvo menor de seus objetivos, na série de livros didáticos usados em aula, Estados Unidos e Inglaterra são culturas-alvo fortemente difundidas ao longo das lições.

Como já foi discutido anteriormente, a noção de ILF desconstrói a possibilidade de haver um único centro normativo. Assim, a língua se perde daqueles que são tidos como seus donos, os falantes nativos, e se democratiza para toda a comunidade global que a utiliza. No entanto, nas representações dos alunos isso parece não se confirmar. Em outra pergunta desenvolvida para os questionários aplicados, buscou-se analisar se os participantes associam a língua inglesa com países específicos. O resultado, que pode ser observado no Gráfico 11.4, nos mostra que, enquanto a maior parte dos alunos relaciona o inglês à países como EUA e Inglaterra, a maioria dos professores ${ }^{6}$ não estabelece associação alguma,

\footnotetext{
6 Tanto professores como alunos apontaram mais de um país ao associar a língua com países específicos.
} 
justificando em suas respostas que, devido ao status internacional, o inglês não é visto por eles como um idioma pertencente a nações específicas, como pode ser notado na fala de uma professora: "Não associo a algum país específico, pois eu vejo o quanto o inglês é uma das principais línguas para comunicação, que mesmo em países onde não é uma língua oficial é possível se comunicar nesses contextos com o inglês" (questionário professor 1).

Apesar de a maioria dos alunos ter associado a língua a algum país específico, alguns reconhecem seu status de língua franca. Como exemplo, podemos citar a Aluna 1: "alguns países me vêm à mente quando penso em falantes da língua inglesa: Estados Unidos, Canadá, Inglaterra e Austrália, embora atualmente tenha se tornado uma língua global" (questionário aluna 1), opinião compartilhada pelo Aluno 2: "não associo. Antes associava muito aos Estados Unidos e à Inglaterra, mas com o passar do tempo passei a ver o inglês como língua internacional, de pessoas que querem se comunicar, independentemente de seu país de origem" (questionário aluno 2).

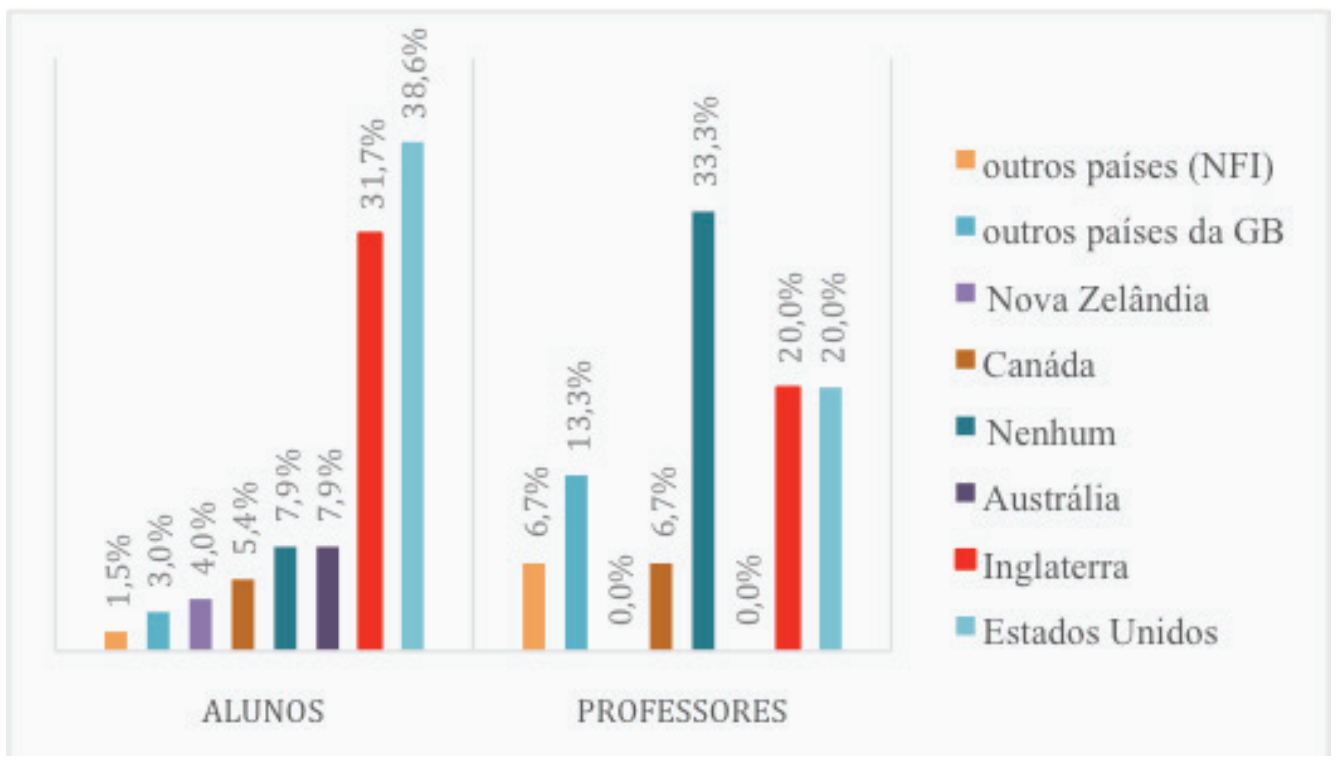

Figura 11.4 - Relação idioma/pais.

A partir das respostas apresentadas na Figura 11.4, é interessante pensar nas implicações do que foi apontado na Figura 11.2, sobre os usos do inglês fora da sala de aula, em conjunto com as respostas dos alunos no que diz respeito às associações da língua inglesa com países específicos. A comparação entre os gráficos evidencia um contrassenso entre o uso e as representações da língua inglesa, já que, embora amplamente usado como uma língua franca em espaços 
virtuais de interação, ainda é vista pelos alunos como pertencente aos Estados Unidos ou à Inglaterra. A partir disso, pode-se concluir que, apesar dos usos do inglês se aproximarem da noção de ILF, as crenças e as representações sobre essa língua seguem uma via contrária.

Essa visão associada a países específicos também pode ser amplamente notada no material didático. Ao analisar o conteúdo presente nos livros Interchange e American Inside Out, foi possível perceber uma grande valorização da cultura norte-americana e, em menor escala, da inglesa. Em alguns momentos no decorrer do livro, é possível encontrar aspectos culturais de países onde o inglês não é a língua materna, porém, o foco sempre recai nos costumes e hábitos americanos. É possível, ainda, perceber que os áudios de ambos os livros apresentam uma padronização das variedades linguísticas, representando uma versão homogênea da realidade linguística dos países retratados. Ao serem questionados se conseguem perceber diferentes variedades do inglês nos materiais de áudio utilizado em aula, $68 \%$ dos alunos afirmaram que sim e $32 \%$ afirmaram que não. Um aluno apontou que há certa dificuldade de diferenciar variedades linguísticas, pois parece haver uma padronização de áudios nos materiais didáticos: "nos áudios dos livros que usamos acho complicado, pois parece meio 'padronizado"” (questionário aluno 3).

Direcionando a discussão para as repercussões do ILF na pronúncia do inglês, questionamos os alunos se eles almejavam alguma aproximação de um falar nativo específico ao estudar o idioma ou se a existência de marcas do português brasileiro na pronúncia do inglês seria uma preocupação. Metade dos participantes da pesquisa afirmou não se preocupar com a pronúncia abrasileirada, considerando-a como constituinte de sua identidade como falante de uma língua franca. Para esse grupo de informantes, o importante é ser compreendido e, portanto, a inteligibilidade é o objetivo fundamental na aprendizagem do idioma:

Devemos respeitar o sotaque de cada nacionalidade. O certo é falar corretamente. (questionário aluno 4)

Não tento adaptar. Acho que sotaque é algo pessoal. Assim como um americano não deixa de ter sotaque ao falar português. Tento apenas aprender a pronúncia correta para poder ser compreendido. (questionário aluno 5)

Não é uma preocupação minha, pois sei que meu sotaque vai ser sempre o brasileiro. (questionário aluno 6)

Porém, enquanto alguns alunos consideram a influência da L1 na pronúncia do inglês como um elemento identitário, priorizando a inteligibilidade e não a imitação de uma proficiência nativa, outros veem a influência da língua materna como um problema (aluno 7). É notável que, para esses sujeitos, o falante nativo ainda é tido como o modelo a ser seguido (aluno 8): 
Sim. Quando falo com a Inglaterra procuro ter essa empatia. Quando falo com os USA, mudo a fala para American pronunciation. (questionário aluno 7)

É uma preocupação, eu não quero falar com sotaque manezinho ou brasileiro de maneira geral. (questionário aluno 8)

Procuro adaptar minha fala mais ao inglês dos EUA, talvez pelos muitos filmes de Hollywood vistos. (questionário aluno 10)

A fala da aluna 10 evidencia que, além da influência exercida pelo livro didático na visão dos alunos quanto às variedades linguísticas, a mídia também se constitui como um forte elemento influenciador. Retomando a Figura 11.2, vemos que grande parte dos alunos mantém contato com a língua por meio de filmes e séries que, na maioria das vezes, são produções hollywoodianas. Todos esses fatores somados - a mídia, os programas de áudio e livro didático usado em aula - formam uma rede de representação do inglês como uma língua pertencente a países específicos. A partir disso, é possível justificar a visão de alguns dos alunos quanto à resistência em aceitar seus sotaques como uma variedade legítima de uma língua franca, não entendendo a influência da L1 como constituinte identitário, mas como um traço que deve ser apagado.

Pode-se também pensar na influência que a visão dos professores exerce sobre os alunos. Metade dos professores investigados afirma não tentar adaptar a fala dos alunos a uma variedade ou outra.

Tento conscientizar os alunos de que o sotaque faz parte de sua identidade, que não importa mais sermos próximos a grupo especifico, e sim produzir linguagem que seja compreendida por todos. Não adapto minha fala, falo exatamente como aprendi, mas também não imponho mudanças nas falas dos alunos se as mesmas são variações aceitáveis. (questionário professora 5)

A atitude dos professores em não tentar adaptar a fala dos alunos a uma variedade específica demonstra uma preocupação com a inteligibilidade, e não com a aproximação a um falante nativo idealizado. Esta é, também, uma abordagem pedagógica que se aproxima do paradigma de ensino que considera o ILF como uma variedade a ser ensinada. O desafio, portanto, passa a ser a implementação de tais ideias em sala de aula, uma vez que muitos cursos de idioma no Brasil, como é o caso do contexto investigado, são calcados em materiais didáticos que trazem uma perspectiva contrária à noção de ILF. 


\subsection{CONSIDERAC̣ÕES FINAIS}

O presente estudo teve o objetivo de investigar as repercussões do ILF em um contexto formal de ensino, atentando para a visão de professores e alunos quanto ao assunto. Para tanto, buscamos responder de que modo as representações e práticas de alunos e professores apontam para uma aproximação ou distanciamento da noção de ILF como uma variedade linguística

Ao longo da análise dos dados coletados por meio de questionários aplicados a 104 alunos e oito professores de inglês do Curso Extracurricular da UFSC, pôde-se observar que, embora os alunos usem o inglês como língua franca fora do contexto de sala de aula, suas crenças e representações continuam calcadas na noção de inglês como uma língua estrangeira, pertencente ao falante nativo.

Em sala de aula, mesmo os professores tendo enfatizado que a noção de ILF trouxe implicações para suas práticas didáticas, como o uso de materiais adicionais que busquem conscientizar os aprendizes sobre o status internacional do inglês, a maior parte dos alunos ainda percebe as variedades dos EUA e da Inglaterra como as mais representadas nos programas de áudio reproduzidos em aula. Parte disso se deve ao fato de que muitos dos áudios utilizados pelos professores são provenientes dos livros didáticos adotados pelo curso, cuja abordagem reforça a compreensão de uma cultura específica. A partir disso, torna-se pertinente refletir até que ponto a realidade fora da sala de aula, em que o inglês é usado pelos alunos como uma língua franca, é considerada como ponto de partida para a elaboração das aulas de inglês e mesmo para a escolha de livros didáticos.

Pôde-se observar também que questões pertinentes à influência da L1 na pronúncia do inglês e ao ensino de pronúncia na perspectiva do ILF ainda levantam uma série de problematizações. De um lado, alunos que veem no falante nativo um modelo-alvo de proficiência e qualquer traço de sua língua materna como algo que deve ser apagado; de outro, professores que se preocupam em desconstruir tais percepções, mas que se deparam com materiais didáticos que insistem em uma representação do inglês que não se conforma com a noção de ILF. Vale ressaltar que a elaboração de livros e programas de áudio que enfatizem a compreensão de uma cultura específica não é, em si, um problema. No entanto, é relevante pensar se tais materiais se configuram como uma ferramenta de apoio na implementação de uma abordagem pedagógica que considere a realidade dos alunos como falantes de uma língua franca.

O presente estudo limitou-se a investigar a realidade de um curso livre de línguas. No entanto, outros contextos formais de ensino no Brasil podem ser igualmente investigados. Além disso, a coleta de dados foi desenvolvida apenas com base em questionários. Assim, outros métodos de coleta, como observações de sala de aula, entrevistas e testes de percepção, podem ser igualmente 
implementados em pesquisas futuras a fim de se obter um resultado final mais holístico na questão do ILF e suas implicações na sala de aula.

\subsection{REFERÊNCIAS}

BRASIL. Parâmetros Curriculares Nacionais: terceiro e quarto ciclos do ensino fundamental: língua estrangeira. Brasília: MEC/Secretaria de Educação Fundamental, 1998.

. Guia de livros didáticos: PNLD 2015. Brasília, DF: MEC/SEB, 2015.

BYRAM, M. Teaching and assessing intercultural communicative competence. Clevedon: Multilingual Matters, 1997.

COOK, V. Going beyond the native speaker in language teaching. TESOL Quarterly, Washington, DC, v. 33, n. 2, p. 185-209, 1999.

CORBETT, J. An Intercultural Approach to English Language Teaching. New York: Multilingual Matters, 2003.

CRUZ, N. C. The (un)intelligibility of "comfortable" produced by a Brazilian speaker of English. Speak out! Newsletter of the IATELFL Pronunciation SIG, v. 33, 2006, p. 9-13.

. Pronúncia no contexto de inglês língua franca: inteligibilidade da fala de um japonês para ouvintes brasileiros. Anais do III Congresso Internacional da ABRAPUI. Florianópolis, 2012.

CRYSTAL, D. English as a global language. [S.I]: Cambridge University Press, 2003.

FIRTH, A. The discursive accomplishment of normality. On 'lingua franca' English and conversation analysis. Journal of Pragmatics, Amsterdam, v. 26, p. 237-259, 1996.

FRIEDRICH, P.; MATSUDA, A. When five words are not enough: a conceptual and terminological discussion of English as a lingua franca. International Multilingual Research Journal, Mahwah, v. 4, n. 1, p. 20-30, 2010.

GIMENEZ, T. Eles comem cornflakes, nós comemos pão com manteiga: espaços para a reflexão sobre cultura na sala de aula de língua estrangeira. Anais do IX Encontro de Professores de Línguas Estrangeiras - IX EPLE. Londrina: APLIEPAR, 2001. p. 107-114.

HOUSE, J. Misunderstanding in intercultural communication: interactions in English as a lingua franca and the myth of mutual intelligibility. In: GNUTZMANN, C. (Ed.). Teaching and learning English as a global language. Tubingen: Stauffenburg, 1999. p. 73-89.

. Pragmatic competence in lingua franca English. In: KNAPP, K.;

HULMBAUER, C. et al. Introducing English as a lingua franca (ELF): 
precursor and partner in intercultural communication. Synergies Europe, 2008. p. 25-36. 2007.

JENKINS, J. English as a lingua franca: attitude and identity. Oxford: OUP,

JENKINS, J.; COGO, A.; DEWEY, M. Review of developments in research into English as a lingua franca. Language teaching, v. 44, n. 3, p. 281-315, 2011.

KRAMSCH, C. Language and culture. Oxford: Oxford University Press, 1998.

KUMARAVADIVELU, B. Cultural globalization and language education. New Haven, CT: Yale University Press, 2008.

LIDDICOAT, A. et al. Striving for the third place: intercultural competence through language education. Melbourne: Language Australia, 1999.

MCKAY, S. L. Teaching English as an international language. Oxford: Oxford University Press, 2002.

MEIERKORD, C. Englisch als medium der interkulturellen kommunication: untersuchungen zum Non-native/Non-native-diskurs. Frankfurt: Peter Lang, 1996.

. 'Language stripped bare' or 'linguistic Masala': culture in lingua franca communication. In KNAPP, K; MEIERKORD, C (Eds.). Lingua franca communication. Frankfurt: Peter Lang, 2002. p. 109-133.

PENZ, H. Successful intercultural communication. In: KETEMANN, B; MARKO, G (Eds.). Expanding circles, transcending disciplines, and multimodal texts. Tubigen: Gunther Nar, 2003.

REIS, F.S.; CRUZ, N.C. (Un)intelligibility in the context of English as a lingua franca: a study with French and Brazilian speakers. Intercâmbio. V. 22, p. 35-55, 2010.

SEIDLHOFER, B. Colsing a conceptual gap: the case for a description of English as a lingua franca. Annual Review of Applied Linguistics, v. 24, p. 209239, 2001.

. Understanding English as a lingua franca. Oxford: OUP, 2011. 


\section{ANEXO 1}

\section{Questionário dos professores}

\section{QUESTIONÁRIO}

Car@ participante, o questionário abaixo foi desenvolvido para que você possa falar um pouco sobre algumas questões relacionadas ao ensino de inglês como língua adicional. Esclarecemos que manteremos em anonimato, sob sigilo absoluto, todos os dados que identifiquem os participantes desse estudo. Dessa forma, seu nome não será exposto na análise de dados, mas o preenchimento do campo nome é importante caso haja a necessidade de esclarecermos alguma informação.

\section{Nome:}

Idade:

\section{Formação acadêmica:}

1. Há quanto tempo você leciona inglês?

2. Você costuma se comunicar em inglês quando não está desenvolvendo atividades docentes? Em caso positivo, em quais situações?

3. Ao pensar sobre a língua inglesa, você a associa com algum país específico? Em caso positivo, qual(is) país(es)? Em caso negativo, justifique sua resposta.

4. Ao ensinar inglês no curso de idiomas, há um foco para alguma variedade linguística do inglês? Em caso positivo, explique o porquê de tal preferência.

5. Qual é o livro didático usado em suas aulas?

6. O livro didático usado no curso privilegia alguma variedade linguística específica ou representa formas de falar de vários povos?

7. Você considera relevante conscientizar os alunos sobre a pluralidade de variantes do inglês ao redor do mundo? Em caso positivo, quais recursos metodológicos te ajudam a fazer isso?

8. Ao ensinar a pronúncia do inglês, você tenta adaptar sua fala e a fala dos alunos ao sotaque de algum país específico ou ter um sotaque estrangeiro não é uma preocupação para você?

\section{Muito obrigado pela sua participação!}




\title{
ANEXO 2
}

\author{
Questionário dos alunos
}

\section{QUESTIONÁRIO}

Car@ participante, o questionário abaixo foi desenvolvido para que você possa falar um pouco sobre algumas questões relacionadas ao ensino de inglês como língua adicional. Esclarecemos que manteremos em anonimato, sob sigilo absoluto, todos os dados que identifiquem os participantes desse estudo. Dessa forma, seu nome não será exposto na análise de dados, mas o preenchimento do campo nome é importante caso haja a necessidade de esclarecermos alguma informação.

Nome:

Idade:

\section{Escolaridade:}

1. Há quanto tempo você estuda inglês em espaços formais (escolas regulares ou escolas de idiomas)?

( ) de 1 a 5 anos

( ) de 6 a 10 anos

( ) mais de 10 anos

( ) menos de 1 ano

2. Fora da sala de aula, o seu contato com a língua inglesa acontece principalmente em quais contextos?

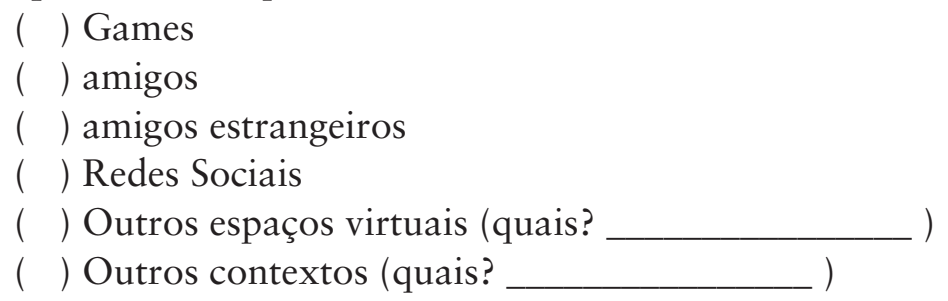

3. Você já se comunicou em inglês fora da sala de aula? Em caso positivo, conte-nos um pouco sobre tal experiência.

4. Dentre os motivos listados abaixo, quais foram aqueles que mais te influenciaram a estudar inglês? (Enumere-os em ordem de relevância: (1) mais relevante e (6) menos relevante)

( ) Trabalho/currículo 
( ) poder se comunicar com pessoas de diferentes nacionalidades (falantes nativos e/ou não nativos do inglês)

( ) viajar para outros países

( ) alcançar melhor compreensão sobre uma cultura específica

( ) provas de proficiência

( ) bolsas de estudos no exterior

5. Ao pensar sobre a língua inglesa, você a associa com algum país específico? Em caso positivo, qual(is) país(es)? Em caso negativo, justifique sua resposta.

6. Ao estudar inglês no curso de idiomas, você consegue notar se há algum sotaque da língua inglesa mais evidente nos programas de áudio ouvidos em aula? Em caso positivo, qual seria?

7. Ao falar inglês, você tenta adaptar sua fala ao sotaque de algum país específico ou ter um sotaque estrangeiro não é uma preocupação para você?

Muito obrigado pela sua participação! 
